\title{
Experimental Study on Interfacial Area Transport of Two-Phase Flow under Vibration Conditions
}

\author{
Xiu Xiao, ${ }^{1}$ Qingzi Zhu, ${ }^{2}$ Shao-Wen Chen, ${ }^{3}$ Mamoru Ishii, ${ }^{2}$ Yajun Zhang, ${ }^{1}$ and Haijun Jia ${ }^{1}$ \\ ${ }^{1}$ Institute of Nuclear and New Energy Technology, Tsinghua University, Beijing 100084, China \\ ${ }^{2}$ School of Nuclear Engineering, Purdue University, 400 Central Drive, West Lafayette, IN 47907, USA \\ ${ }^{3}$ Institute of Nuclear Engineering and Science, National Tsing Hua University, Hsinchu 30013, Taiwan \\ Correspondence should be addressed to Xiu Xiao; xiao-x11@mails.tsinghua.edu.cn
}

Received 19 September 2016; Revised 23 December 2016; Accepted 7 March 2017; Published 22 March 2017

Academic Editor: Rizwan Uddin

Copyright (C) 2017 Xiu Xiao et al. This is an open access article distributed under the Creative Commons Attribution License, which permits unrestricted use, distribution, and reproduction in any medium, provided the original work is properly cited.

\begin{abstract}
An experimental study on air-water two-phase flow under vibration condition has been conducted using double-sensor conductivity probe. The test section is an annular geometry with hydraulic diameter of $19.1 \mathrm{~mm}$. The vibration frequency ranges from $0.47 \mathrm{~Hz}$ to $2.47 \mathrm{~Hz}$. Local measurements of void fraction, interfacial area concentration (IAC), and Sauter mean diameter have been performed along one radius in the vibration direction. The result shows that local parameters fluctuate continuously around the base values in the vibration cycle. Additional bubble force due to inertia is used to explain lateral bubble motions. The fluctuation amplitudes of local void fraction and IAC increase significantly with vibration frequency. The radial distribution of local parameters at the maximum vibration displacement is specifically analyzed. In the void fraction and IAC profiles, the peak near the inner wall is weakened or even disappearing and a strong peak skewed to outer wall is gradually observed with the increase of vibration frequency. The nondimensional peak void fraction can reach a maximum of $49 \%$ and the mean relative variation of local void fraction can increase to more than $29 \%$ as the vibration frequency increases to $2.47 \mathrm{~Hz}$. But the increase of vibration frequency does not bring significant change to bubble diameter.
\end{abstract}

\section{Introduction}

Two-phase flows are frequently encountered in industrial applications. In the present state of the arts, the two-fluid model is considered to be the most detailed and accurate formulation in analyzing the thermofluid dynamics of twophase systems. In two-fluid model, liquid and gas phases are separately described by using two sets of conservation equations for mass, momentum, and energy. The existence of the interfacial transfer terms which represent the mass, momentum, and energy transfer at the liquid-vapor interface is one of the most important characteristics of the two-fluid model formulation. To dynamically predict the interfacial transport phenomena, Kocamustafaogullari and Ishii [1] proposed the interfacial area transport equation (IATE). The IATE is based on statistical mechanics and its concept has been fully established. But the sink and source terms of interfacial area due to bubble interactions are still being developed.
Recent advances in two-phase measurement techniques have stimulated further research on interfacial area transport models. Particularly, the improvements in probe methods [26] allow accurate measurements of local flow parameters, such as void fraction, interfacial area concentration, and interfacial velocity. With the help of these techniques, a rigorous database has been collected for two-phase flow in various flow geometries [7-10].

However, all the above-mentioned experiments were performed under static condition. Earthquakes struck to nuclear reactors frequently in recent years and some even resulted in scram in nuclear power plants $[11,12]$. Many studies have been conducted in consideration of the nuclear reactor safety when an earthquake occurs, including the structural safety design of nuclear reactors and siting of nuclear power plants. But there is little knowledge of thermal fluid characteristics in the reactor system during the earthquake. Two-phase flow is an important phenomenon in reactor core and its behavior is 


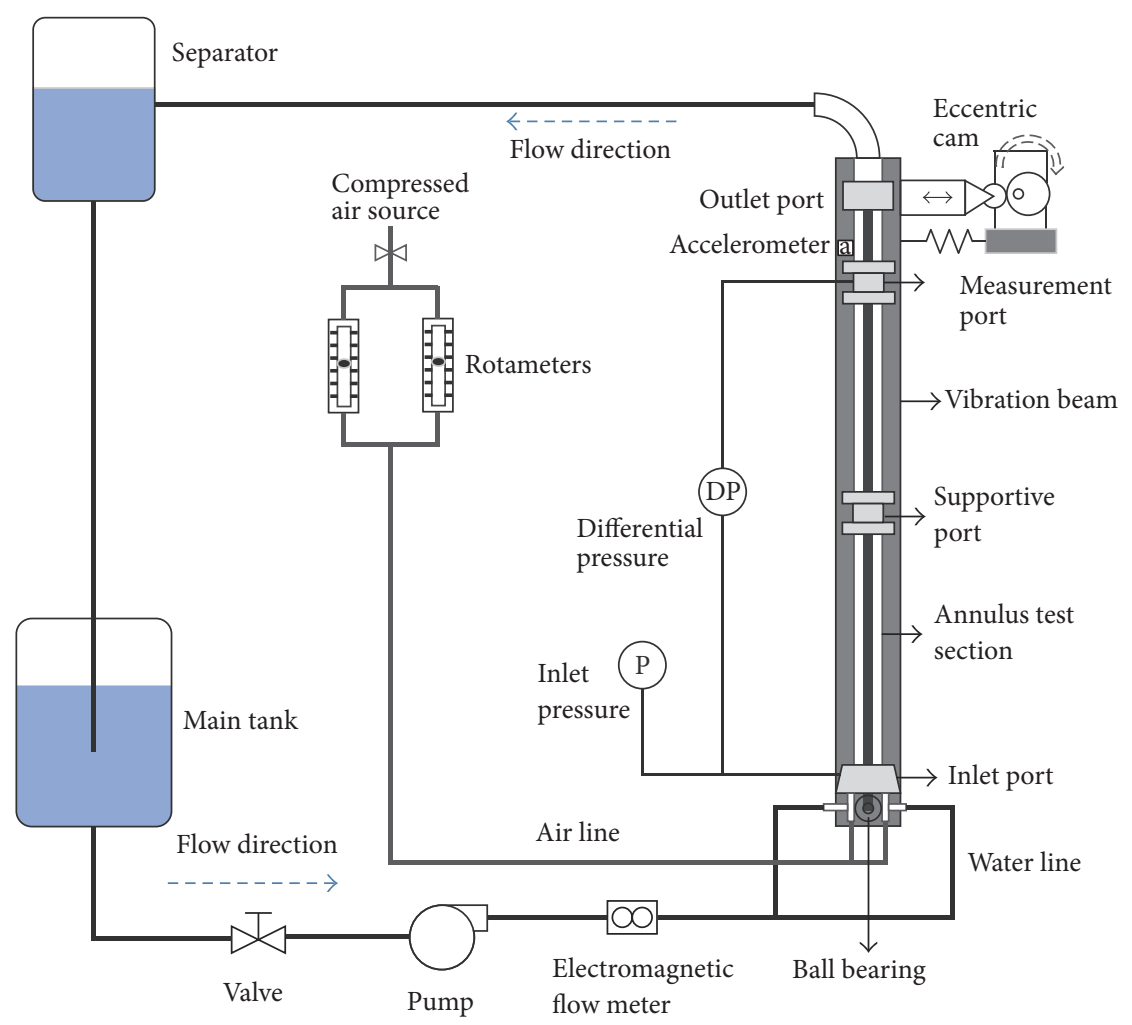

FIGURE 1: Schematic of experimental facility.

closely related to the operation of nuclear reactors. Due to the different properties of the two phases and the complex interactions at phase boundary, the seismic vibration may significantly change the two-phase flow structures in reactor core. This change may result in deterioration in local heat transfer, even critical heat flux (CHF). In addition, the changes in void fraction and interfacial area concentration may further bring reactivity feedback to reactor core and change neutron flux as well as power distribution in the reactor. Therefore, in order to understand the effect of earthquake vibration on nuclear reactor precisely, the study on two-phase flow behaviors under vibration condition is required. Nariai and Tanaka [13] performed experimental study of void fraction in subcooled boiling two-phase flow under oscillating conditions. The void fraction decreased drastically when the vibration frequency reached $10 \mathrm{~Hz}$ or higher. Hibiki and Ishii [14] investigated the effects of flow-induced vibration on local parameters of upward air-water two-phase flow. The flow-induced vibration promoted bubble coalescence and led to increase of Sauter mean diameter and decrease of interfacial area concentration for relatively low superficial liquid velocity. The void fraction profiles also changed from "wall peak" to "core peak" or "transition." Lee et al. [15] performed CHF experiments with vibrating test section. The results showed that the $\mathrm{CHF}$ was enhanced by increasing vibration amplitude and frequency. Chen et al. [16] studied the adiabatic two-phase flow under vibration conditions with impedance meters. It was found that the low-frequency vibration had a limited impact on the time-averaged area-averaged void fraction. However, the instantaneous void fraction signals were affected and the results were shown by fast Fourier transformation (FFT) analysis. Arai et al. [17] performed visualization experiments for vertical bubbly flow in rectangular water tank on which sine wave vibration was applied. The bubble behaviors were affected by oscillation and the cycle of bubble inclination angel was almost the same as the cycle of oscillation table velocity. Xiao et al. [18] conducted preliminary experiment of vibration effect on bubbly two-phase flow. Important phenomena including the variations of local void fraction and interfacial area concentration were proposed. But the detailed influence of vibration parameters on two-phase flow structure was not addressed.

As described above, some studies have been conducted to investigate the vibration effect on two-phase flow. The results indicate that the flow behaviors will be affected by structure vibration. However, experimental data concerning about the detailed variations of local interfacial parameters under vibration condition is still lacking. In the current research, an experiment has been performed to measure the void fraction, interfacial area concentration, and Sauter mean diameter locally using double-sensor conductivity probe under different vibration conditions.

\section{Experimental Apparatus}

2.1. Experimental Facility. The schematic of the experimental facility is shown in Figure 1. The test section is an annular geometry that is formed by a Pyrex glass tube on the outside 
and a stainless steel rod on the inside. The inner rod has a $19.1 \mathrm{~mm}$ outer diameter and the glass tube has a $38.1 \mathrm{~mm}$ inner diameter. The overall length of the flow channel is $2.32 \mathrm{~m}$. A two-phase mixture injection system is located at the bottom of the test section, which consists of a sparger and water flow channel. The sparger is made up of porous material with an average pore size of $10 \mu \mathrm{m}$ and can generate almost uniform bubbles of approximately 1-2 $\mathrm{mm}$ in diameter. During the experiment, filtered and chemically treated water with conductivity of about $300 \mu \mathrm{S} / \mathrm{cm}$ was held in the main tank. Water was driven by a centrifugal pump and controlled by a ball valve and a frequency converter. Air was supplied by a compressor and a pressure regulator was employed to maintain a constant pressure. After flowing through the test section, the air was released into the atmosphere through a separator while water was circulated by the centrifugal pump. The superficial liquid velocity $\left\langle j_{f}\right\rangle$ and superficial gas velocity $\left\langle j_{g}\right\rangle$ ranged from $0.52 \mathrm{~m} / \mathrm{s}$ to $1.03 \mathrm{~m} / \mathrm{s}$ and from $0.195 \mathrm{~m} / \mathrm{s}$ to $0.403 \mathrm{~m} / \mathrm{s}$, respectively. Here, the symbol 〈〉 represents the area-averaged value. The water flow rate was measured using an electromagnetic flow meter with an accuracy of $\pm 1 \%$. Two rotameters with different measuring ranges $\left(0.08-0.57 \mathrm{~m}^{3} / \mathrm{h}\right.$ and $0.28-2.83 \mathrm{~m}^{3} / \mathrm{h}$ ) were used to measure the gas flow rate with an accuracy of $\pm 3 \%$ of full scale. The water temperature was kept at $25 \pm 0.5^{\circ} \mathrm{C}$.

The annulus test section is connected to a vibration module through a rectangular vibration beam. The vibration module mainly consists of a fixed I-beam, a vibration beam, a ball bearing, a sliding track, three damping springs, a 3HP motor, a frequency controller, and an eccentric cam. The vibration beam is driven back and forth by the eccentric cam and damping springs. By controlling the motor speed ( $\mathrm{ms}$, in $\mathrm{rpm}$ ) and using different eccentric wheels, various vibration conditions can be acquired. In view of the earthquake intensity scale and safety operation of the vibration module [16], an eccentric cam with eccentricity of $9.5 \mathrm{~mm}$ is used. The motor speed ranges from $30 \mathrm{rpm}$ to $150 \mathrm{rpm}$. An accelerometer is installed on the vibration beam to measure the vibration acceleration $(a)$ of the test section. The accuracy of the accelerometer is $\pm 1 \%$ of full scale $(2 g$, where $g$ is the gravitational acceleration and $1 \mathrm{~g}=9.8 \mathrm{~m} / \mathrm{s}^{2}$ ).

2.2. Instrumentation. Double-sensor conductivity probe was used to measure local two-phase flow parameters including void fraction, interfacial area concentration, and Sauter mean diameter under both static and vibration conditions. The local time-averaged void fraction was simply the accumulated time during which the sensor was exposed to the gas phase divided by the total sampling time. The bubble interface velocity was calculated by taking into account the distance between the tips of the upstream and downstream sensors to the time difference between the upstream and downstream signal. The interfacial area concentration can be calculated from interface velocity by using some mathematical formulations and statistical considerations. The detailed measurement methodology can be referred to the previous works $[3,19]$.

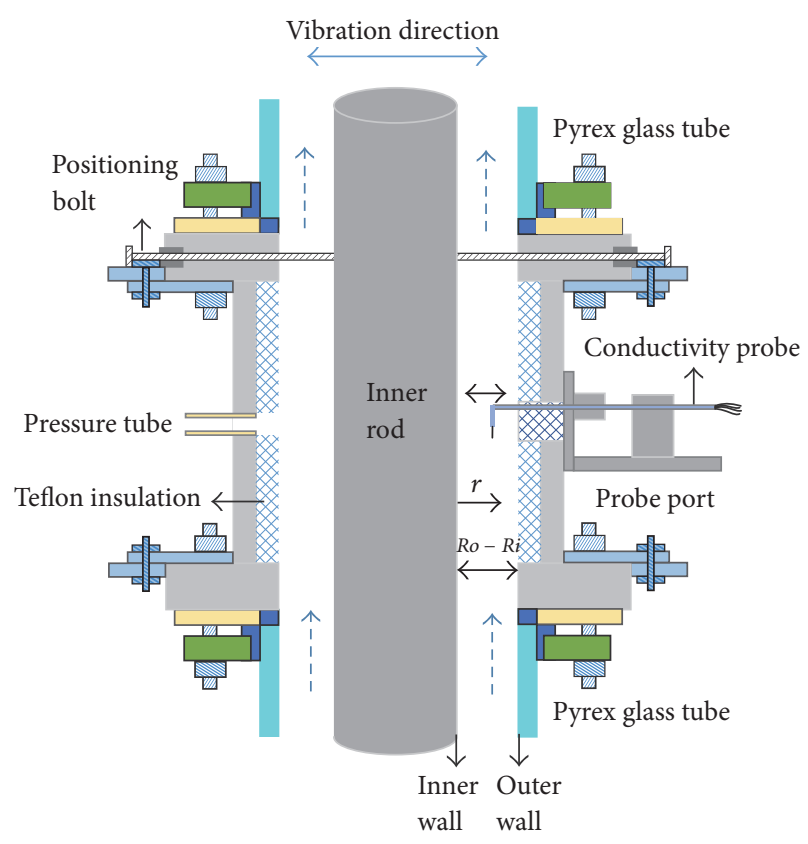

Figure 2: Measurement port.

The measurement port was located at $L / D_{h}=106$, where $L$ is the distance from the measurement port to the inlet port and $D_{h}$ is the hydraulic diameter of the flow channel. The port was designed to support conductivity probe and the probe can be radially traversed in the annulus. Probe measurements were taken along one of the radius in the vibration direction as shown in Figure 2. Local flow measurements using doublesensor conductivity probe were performed at eleven radial locations of $r /\left(R_{o}-R_{i}\right)=0.13,0.18,0.23,0.33,0.43,0.52,0.62$, $0.72,0.82,0.86$, and 0.91 , where $r$ is the radial distance from the inner rod wall and $\left(R_{o}-R_{i}\right)$ is the radial clearance of the annulus. Probe signals were collected at a high sampling frequency of $40 \mathrm{kHz}$. The data acquisition time was adjusted depending on specific flow condition to make sure that at least 1500 bubbles were detected by the leading sensor of the probe in every vibration interval to be defined in Section 3.3. Differential pressure measurement was also taken at the measurement port. The accuracy of the pressure transducer was within $\pm 0.375 \%$ of full measurement range. It is important to note that the probe signals must be synchronized with the vibration signal in order to reveal the vibration effect on local flow parameters in time. To make sure of this, the same data acquisition board was used to acquire output signals from the probe and the accelerometer simultaneously.

In order to verify the accuracy of double-sensor probe measurement, the area-averaged quantities obtained by integrating the local parameters over the flow channel were compared with those measured by other cross-calibration methods such as differential pressure gauge for void fraction and rotameter for superficial gas velocity. The comparison results are shown in Table 1 . The area-averaged superficial gas velocity from probe in Table 1 was calculated based on the local void fraction and local gas velocity measured by the double-sensor probe. Good agreements were obtained 
TABLE 1: Accuracy of probe measurement.

\begin{tabular}{lccccc}
\hline$\langle\alpha\rangle$ by DP $(-)$ & $\langle\alpha\rangle$ by probe $(-)$ & Accuracy of $\langle\alpha\rangle(\%)$ & $\left\langle j_{g}\right\rangle$ by rotameter $(\mathrm{m} / \mathrm{s})$ & $\left\langle j_{g}\right\rangle$ by probe $(\mathrm{m} / \mathrm{s})$ & Accuracy of $\left\langle j_{g}\right\rangle(\%)$ \\
\hline 0.189 & 0.202 & 6.88 & 0.159 & 0.173 & 0.168 \\
0.086 & 0.095 & 10.47 & 0.150 & 0.81 & 12.30 \\
0.206 & 0.225 & 9.22 & 0.369 & 0.327 & 12.84 \\
\hline
\end{tabular}
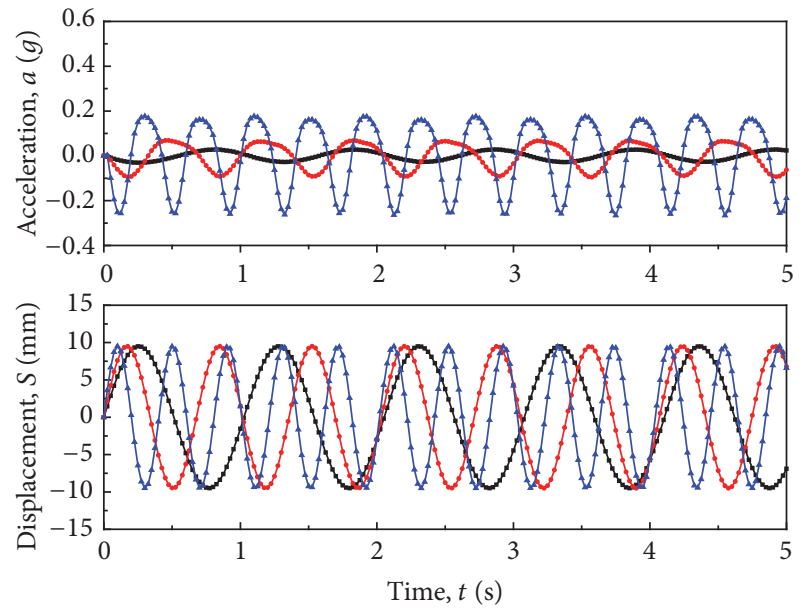

$\begin{aligned} \longrightarrow \mathrm{ms} & =60 \mathrm{rpm} \\ \longrightarrow \mathrm{ms} & =90 \mathrm{rpm} \\ \longrightarrow \mathrm{ms} & =150 \mathrm{rpm}\end{aligned}$

FIGURE 3: Vibration acceleration and displacement profiles under different motor speeds.

with averaged relative deviations of $10 \%$ and $11.5 \%$ for area-averaged void fraction and superficial gas velocity, respectively. The benchmark experiments for double-sensor conductivity probe have also been performed in earlier studies $[20,21]$. The relative difference of interfacial area concentration between the image processing method and doublesensor probe was within $10 \%$. Sauter mean diameter depends on void fraction and interfacial area concentration. The propagated uncertainty for Sauter mean diameter is $19.7 \%$.

\section{Results and Discussion}

3.1. Acceleration Analysis. The vibration frequency of the test section was controlled by the motor speed. Five motor speeds which ranged from $30 \mathrm{rpm}$ to $150 \mathrm{rpm}$ were adopted during the vibration experiment. Vibration acceleration was measured by the accelerometer. Signal filtering and FFT methods were used to process the acceleration signals. The vibration acceleration changes linearly along the length of the test section. In the following, the vibration parameters stand for the vibration condition at the measurement location of $L / D_{h}=106$. Figure 3 shows the vibration acceleration and displacement profiles under different motor speeds. Here, the test section is defined to vibrate around $z$-axis and counterclockwise around $z$-axis is defined as the positive vibration direction. It can be seen from Figure 3 that the vibration parameters vary periodically with the vibration motion. The
TABLE 2: Vibration parameters under five motor speeds.

\begin{tabular}{ccccc}
\hline $\begin{array}{l}\text { Amplitude Motor speed } \\
A(\mathrm{~mm})\end{array}$ & $\begin{array}{c}\text { Frequency } \\
\mathrm{ms}(\mathrm{rpm})\end{array}$ & $\begin{array}{c}\text { Acceleration } \\
(\mathrm{Hz})\end{array}$ & $\begin{array}{c}\text { Acceleration } \\
\left|a_{m 1}\right|(g)\end{array}$ & $\left|a_{m 2}\right|(g)$ \\
\hline \multirow{4}{*}{9.5} & 30 & 0.469 & 0.01 & 0.014 \\
& 60 & 0.969 & 0.031 & 0.047 \\
& 90 & 1.472 & 0.065 & 0.094 \\
& 120 & 1.973 & 0.110 & 0.171 \\
& 150 & 2.473 & 0.168 & 0.264 \\
\hline
\end{tabular}

fluctuation amplitude of the vibration acceleration increases with the motor speed and the vibration acceleration can reach up to $0.264 \mathrm{~g}$ as the motor speed increases to $150 \mathrm{rpm}$. Table 2 summarizes the main vibration parameters under five motor speeds. The subscripts $m 1$ and $m 2$ represent the maximum values in the positive and negative vibration directions, respectively. The vibration of the test section was driven by eccentric cam and damping springs. The force exerted by damping springs may change its direction during vibration cycle, resulting in the difference between $\left|a_{m 1}\right|$ and $\left|a_{m 2}\right|$.

3.2. Local Time-Averaged Flow Parameters. Local two-phase flow measurements using double-sensor conductivity probe were first performed under static condition. Figure 4 shows the radial distributions of local time-averaged void fraction $(\alpha)$, interfacial area concentration $\left(a_{i}\right)$, and Sauter mean diameter $\left(D_{\mathrm{sm}}\right)$. For the flow condition of $\left\langle j_{f}\right\rangle=0.52 \mathrm{~m} / \mathrm{s}$ and $\left\langle j_{g}\right\rangle=0.195 \mathrm{~m} / \mathrm{s}$, intermediate peak characterized as broad peak in void fraction near the channel wall and plateau with medium void fraction around the channel center is observed. When $\left\langle j_{f}\right\rangle$ is increased to $1.03 \mathrm{~m} / \mathrm{s}$, the radial position of the void fraction peak is moved toward the channel wall. The increase in $\left\langle j_{f}\right\rangle$ also augments the void fraction at the peak and makes the void fraction peak sharp. For the flow condition of $\left\langle j_{f}\right\rangle=1.03 \mathrm{~m} / \mathrm{s}$, bubble coalescence occurs as $\left\langle j_{g}\right\rangle$ increases to $0.403 \mathrm{~m} / \mathrm{s}$. The radial migration of bubbles plays an important role in the evolution of local flow structure. Relatively large bubbles with Sauter mean diameter greater than about $5 \mathrm{~mm}$ tend to concentrate at the channel center, resulting in changing the phase distribution from intermediate peak to core peak. Since the interfacial area concentration is proportional to void fraction and inversely proportional to Sauter mean diameter, the profiles of interfacial area concentration and void fraction are very similar if the Sauter mean diameter is radially uniform. For $\left\langle j_{g}\right\rangle=0.195 \mathrm{~m} / \mathrm{s}$, the Sauter mean diameter profiles are almost uniform along the radius with some decrease near the channel wall. This yields a greater peak-to-average ratio in the interfacial area concentration profiles. But for $\left\langle j_{f}\right\rangle=1.03 \mathrm{~m} / \mathrm{s}$ and $\left\langle j_{g}\right\rangle=0.403 \mathrm{~m} / \mathrm{s}$, the 

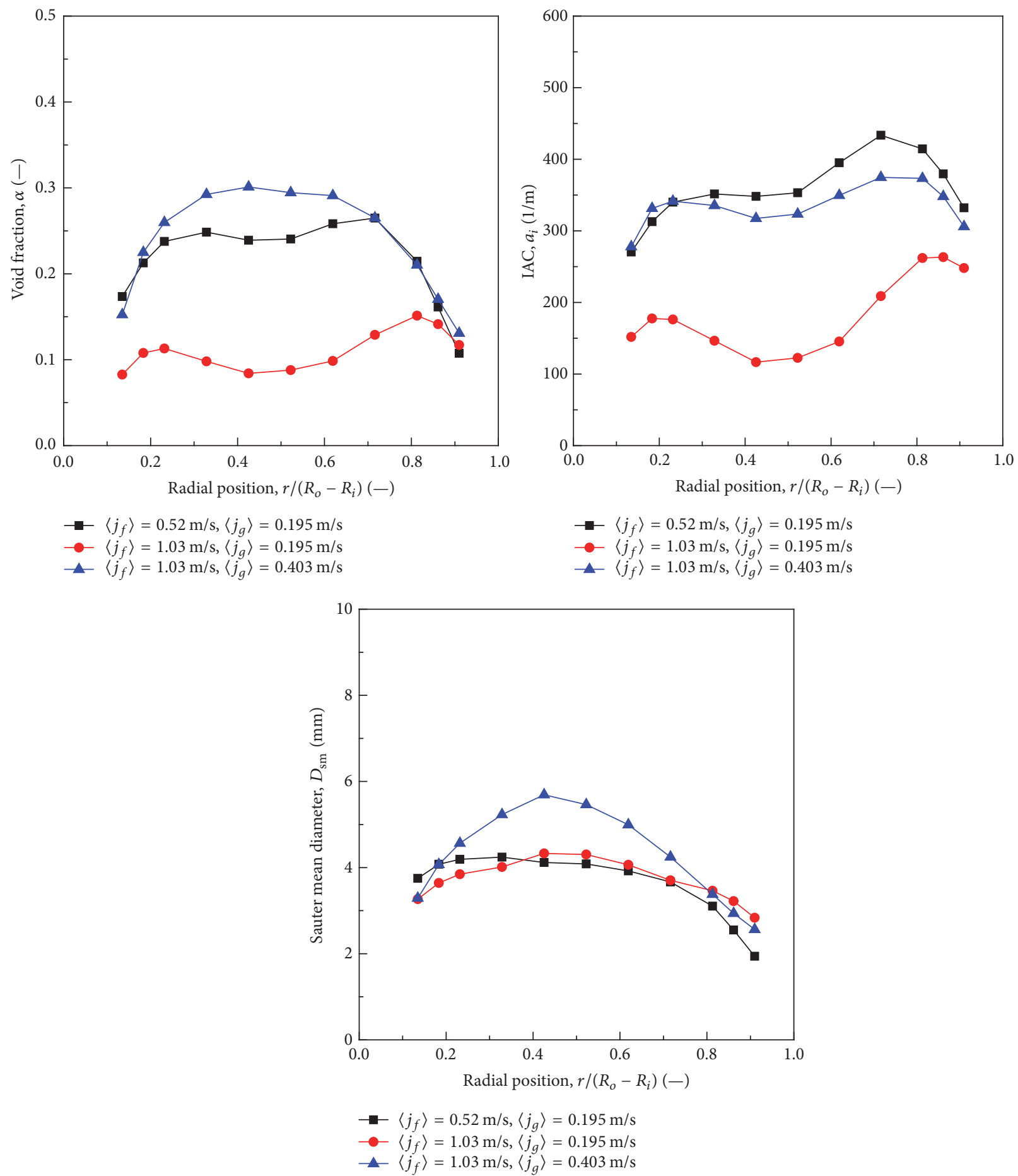

FIGURE 4: Profiles of local time-averaged flow parameters under static condition.

formation of big cap bubbles decreases the interfacial area concentration. As a result, the profile of the IAC is different from the void fraction profile. The Sauter mean diameter has a core peak distribution, resulting in a concave profile of the interfacial area concentration near the channel center for this flow condition.

The vibration experiments were then carried out in sequence from low to high frequency. Structure vibration may stimulate phase interactions and interfacial transport in two-phase flow. In order to verify the vibration effect on local time-averaged flow parameters, the parameters measured under vibration conditions are compared with those measured under static condition. The mean relative variation (MRV), which represents the average of local time-averaged flow parameters' variation in the 11 radial measurement locations caused by vibration, is defined. Here, the MRV of 
void fraction, interfacial area concentration, and Sauter mean diameter have the following expressions:

$$
\begin{gathered}
\operatorname{MRV}_{\alpha}=\frac{1}{N} \sum_{i}\left\{\frac{\left|\alpha_{f}-\alpha_{f=0}\right|}{\alpha_{f=0}}\right\}_{i} \times 100 \%, \\
\operatorname{MRV}_{a_{i}}=\frac{1}{N} \sum_{i}\left\{\frac{\left|a_{i, f}-a_{i, f=0}\right|}{a_{i, f=0}}\right\}_{i} \times 100 \%, \\
\operatorname{MRV}_{D_{\mathrm{sm}}}=\frac{1}{N} \sum_{i}\left\{\frac{\left|D_{\mathrm{sm}, f}-D_{\mathrm{sm}, f=0}\right|}{D_{\mathrm{sm}, f=0}}\right\}_{i} \times 100 \%,
\end{gathered}
$$

where $N$ is the total number of radial measurement locations and $i$ denotes the $i$ th radial measurement location; the subscripts $f$ and $f=0$ denote the local time-averaged values measured under vibration condition with vibration frequency of $f$ and under static condition, respectively. Figure 5 shows the vibration effect on time-averaged flow parameters. For the flow condition with relatively low void fraction (i.e., $\left\langle j_{f}\right\rangle=1.03 \mathrm{~m} / \mathrm{s}$ and $\left\langle j_{g}\right\rangle=0.195 \mathrm{~m} / \mathrm{s}$ ), the change in local time-averaged void fraction due to vibration is bigger than other flow conditions and the MRV of void fraction increases with vibration frequency $f$. This phenomenon becomes insignificant with the increase of void fraction. The MRV of interfacial area concentration shows similar profiles. In general, the vibration effect on local time-averaged flow parameters is very limited with MRV less than $8 \%$. Particularly, according to the analysis in every radial measurement location, the variation of local time-averaged parameters is within $\pm 10 \%$. This can be explained from two aspects. On one hand, the pressure fluctuation caused by the vibration of the test section is still low compared to the hydrostatic head and friction loss. On the other hand, the instantaneous change in local flow parameters resulting from structure vibration is balanced out by the time averaging process. Therefore, an adequate analytical method is needed to reveal the transient variations of local flow parameters.

\subsection{Variation of Local Flow Parameters under Vibration} Condition. The test section vibrates periodically with preset frequency during vibration experiment. In order to obtain the transient variations of local two-phase flow parameters under vibration condition, the vibration interval is defined. Specifically, the vibration interval represents a continuously finite interval where the flow behavior is assumed to remain the same in the vibration cycle. Local flow parameters measured by conductivity probe are averaged values over a sufficient amount of time for statistical convergence. Therefore, the same vibration intervals in every vibration cycle are grouped together and the time-averaged flow parameters in such a combined interval are used to stand for the parameters at the instantaneous vibration position. There are two considerations involved in selection of the vibration interval. One is that the interval cannot be too large to keep the above assumption reasonable. The second is that the interval cannot be too small. The total sampling time of each combined interval should be sufficiently large to minimize statistical errors [22]. Based on these two considerations, the vibration cycle is divided into twelve vibration intervals with each vibration interval covering $\pi / 6$ vibration phase angle. In the present experiment, the vibration parameter is measured by the accelerometer. The acceleration signal as shown in Figure 3 is first analyzed to provide information for separating vibration cycle into twelve vibration intervals. Since the probe signals are collected simultaneously with the acceleration signal, the probe signals are then separated and regrouped into twelve parts according to the above information. As a result, the local flow parameters at each vibration interval as well as the variation of local parameters in the vibration cycle can be determined.

Figure 6 shows the variation of local flow parameters at five representative radial locations in the vibration cycle. As a comparison, the respective local time-averaged flow parameters measured under static condition are presented as dotted lines in this figure. Since the probe measurements were taken only along one radius as indicated in Figure 2, the variation of local parameters along this radius is mainly discussed in this study. Plus, the inner wall and outer wall in the following denote the radial locations where $r /\left(R_{o}-\right.$ $\left.R_{i}\right)=0$ and 1 , respectively. It can be seen from Figure 6 that the local parameters fluctuate continuously around the dotted lines in the vibration cycle. In the flow region near the inner wall $\left(r /\left(R_{o}-R_{i}\right)=0.13\right.$ and 0.33$)$, the void fraction and interfacial area concentration decrease as the test section moves from $S_{m 2}$ to $S_{m 1}$ and increase as the test section moves from $S_{m 1}$ to $S_{m 2}$. Opposite trend can be observed in the flow region near the outer wall $\left(r /\left(R_{o}-R_{i}\right)=0.72\right.$ and 0.91$)$. The fluctuation amplitude of void fraction and interfacial area concentration around the channel center $\left(r /\left(R_{o}-R_{i}\right)=\right.$ $0.52)$ is relatively small. This finding can be attributed to the significant radial migration of bubbles under vibration, which mainly results from the coaction of forces acting on bubbles. Some researchers [23-25] have reviewed the forces acting on bubbles in lateral direction under static condition. The lateral motion of bubbles is mainly determined by three forces: the wall force, the lift force, and the turbulent dispersion force. Bubble coalescence and breakup process can also influence bubble motions. In the vibration experiment, there are two additional forces acting on bubbles. One is the lateral component of buoyancy force. It is directed toward outer wall and inner wall, respectively, when the test section is in the positive and negative vibration directions. In fact, this force is negligible since the inclination angle, which is defined as the ratio of vibration displacement to the total length of the test section, is rather small. The other one is the lateral force due to inertia. This force plays an important role in radial bubble motion and its magnitude and direction vary continuously with vibration acceleration. The sum of bubble forces projected to the radial direction directly determines the variation of local flow parameters.

As the test section moves from $S=0$ to $S=S_{m 1}$, the vibration acceleration of the test section has a negative direction. The liquid phase tends to accumulate near the inner wall under inertia effect and the bubbles are driven toward outer wall. As a result, the local void fraction decreases in the radial locations of $r /\left(R_{o}-R_{i}\right)=0.13$ and 0.33 and increases in the radial locations of $r /\left(R_{o}-R_{i}\right)=0.72$ and 0.91 during this 

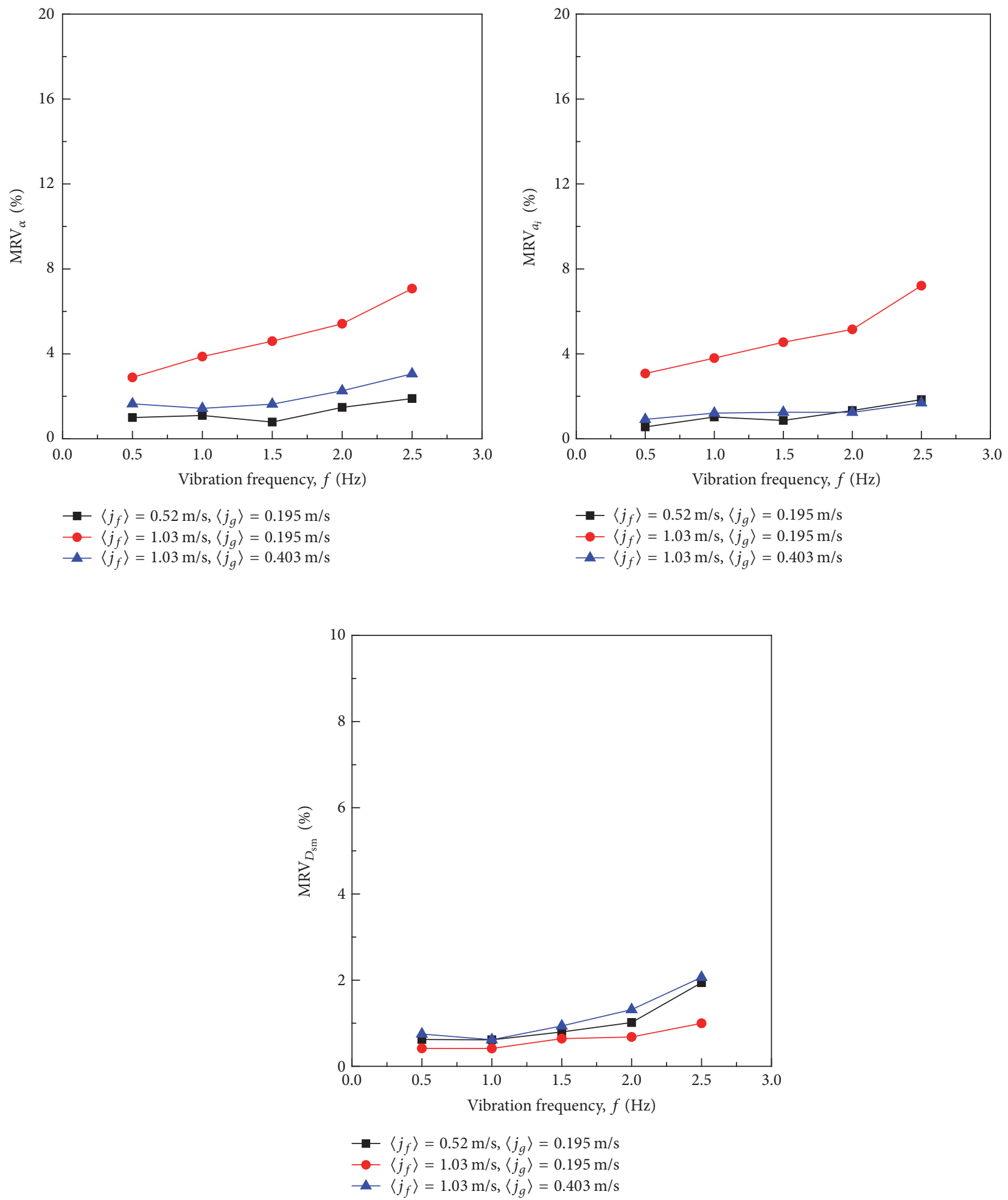

FIGURE 5: Vibration frequency effect on MRV of time-averaged flow parameters.

stage. With the bubbles moving to the outer wall, the radial gradient of void fraction becomes higher and the turbulent dispersion force is enhanced. As the test section moves from $S=S_{m 1}$ to $S=0$, the vibration acceleration keeps its negative direction but its value decreases from $\left|a_{m 2}\right|$ to almost 0 . During this stage, the turbulent dispersion force gradually exceeds the additional bubble force caused by inertia and bubbles begin to reverse their direction to move toward inner wall. Therefore, the local void fraction starts to increase near the inner wall region and decrease near the outer wall at a certain moment in this stage. The opposite trend can be expected during the other half period of the vibration cycle. 

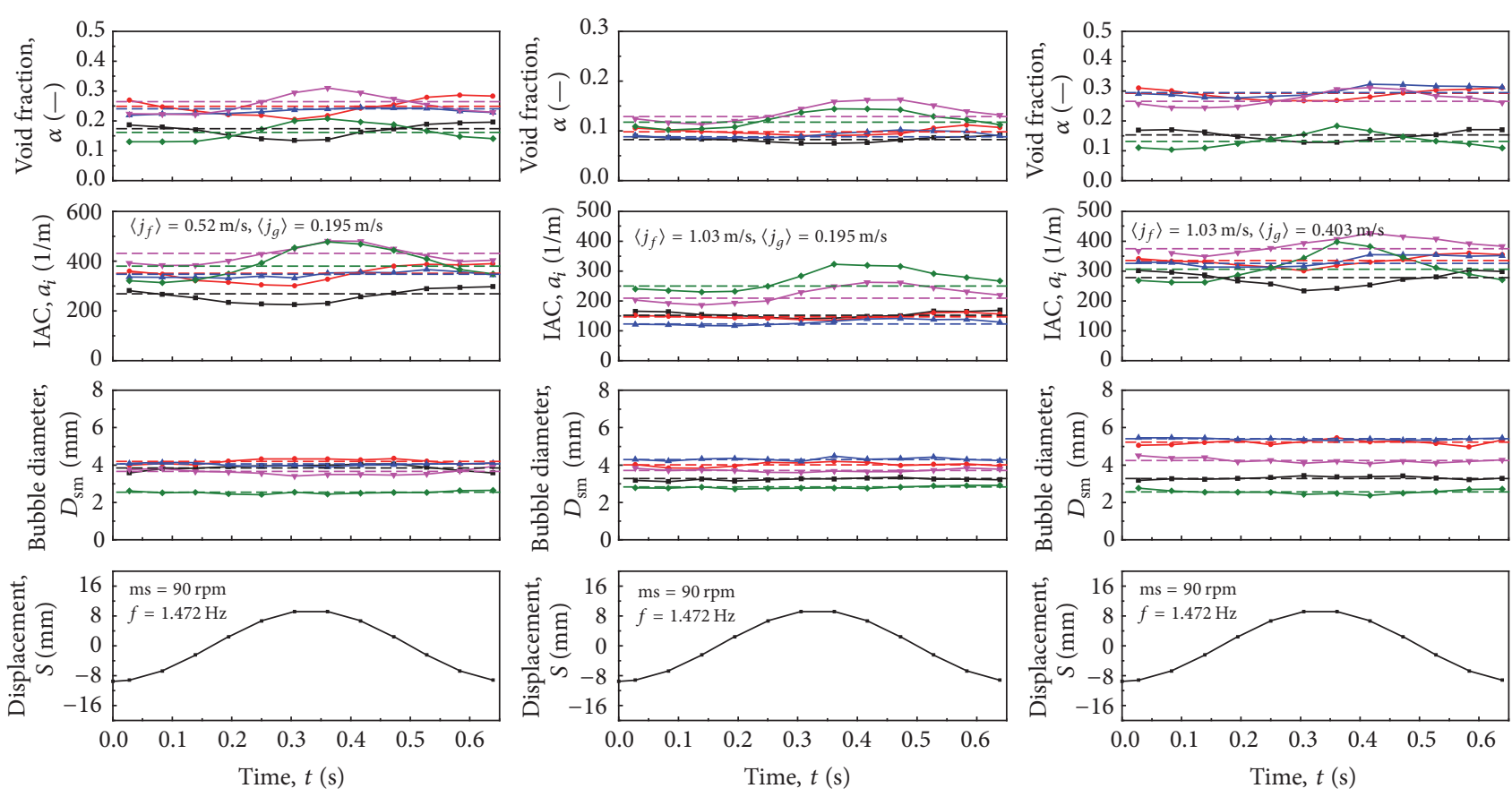

$$
\begin{aligned}
& \rightarrow r /\left(R_{o}-R_{i}\right)=0.13 \\
& \because r /\left(R_{o}-R_{i}\right)=0.52 \\
& \because r /\left(R_{o}-R_{i}\right)=0.91 \\
& \because r /\left(R_{o}-R_{i}\right)=0.33 \\
& \because r /\left(R_{o}-R_{i}\right)=0.72
\end{aligned}
$$

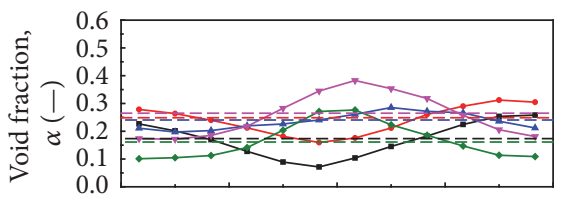

$$
\begin{aligned}
& \longrightarrow\left(r-R_{i}\right) /\left(R_{o}-R_{i}\right)=0.1 \\
& \longrightarrow\left(r-R_{i}\right) /\left(R_{o}-R_{i}\right)=0.5 \\
& \longrightarrow\left(r-R_{i}\right) /\left(R_{o}-R_{i}\right)=0.9 \\
& \longrightarrow\left(r-R_{i}\right) /\left(R_{o}-R_{i}\right)=0.3 \\
& \longrightarrow\left(r-R_{i}\right) /\left(R_{o}-R_{i}\right)=0.7
\end{aligned}
$$

$$
\begin{aligned}
& \longrightarrow r /\left(R_{o}-R_{i}\right)=0.13 \\
& \longrightarrow r /\left(R_{o}-R_{i}\right)=0.52 \\
& \because r /\left(R_{o}-R_{i}\right)=0.91 \\
& \because r /\left(R_{o}-R_{i}\right)=0.33 \\
& \longrightarrow r /\left(R_{o}-R_{i}\right)=0.72
\end{aligned}
$$
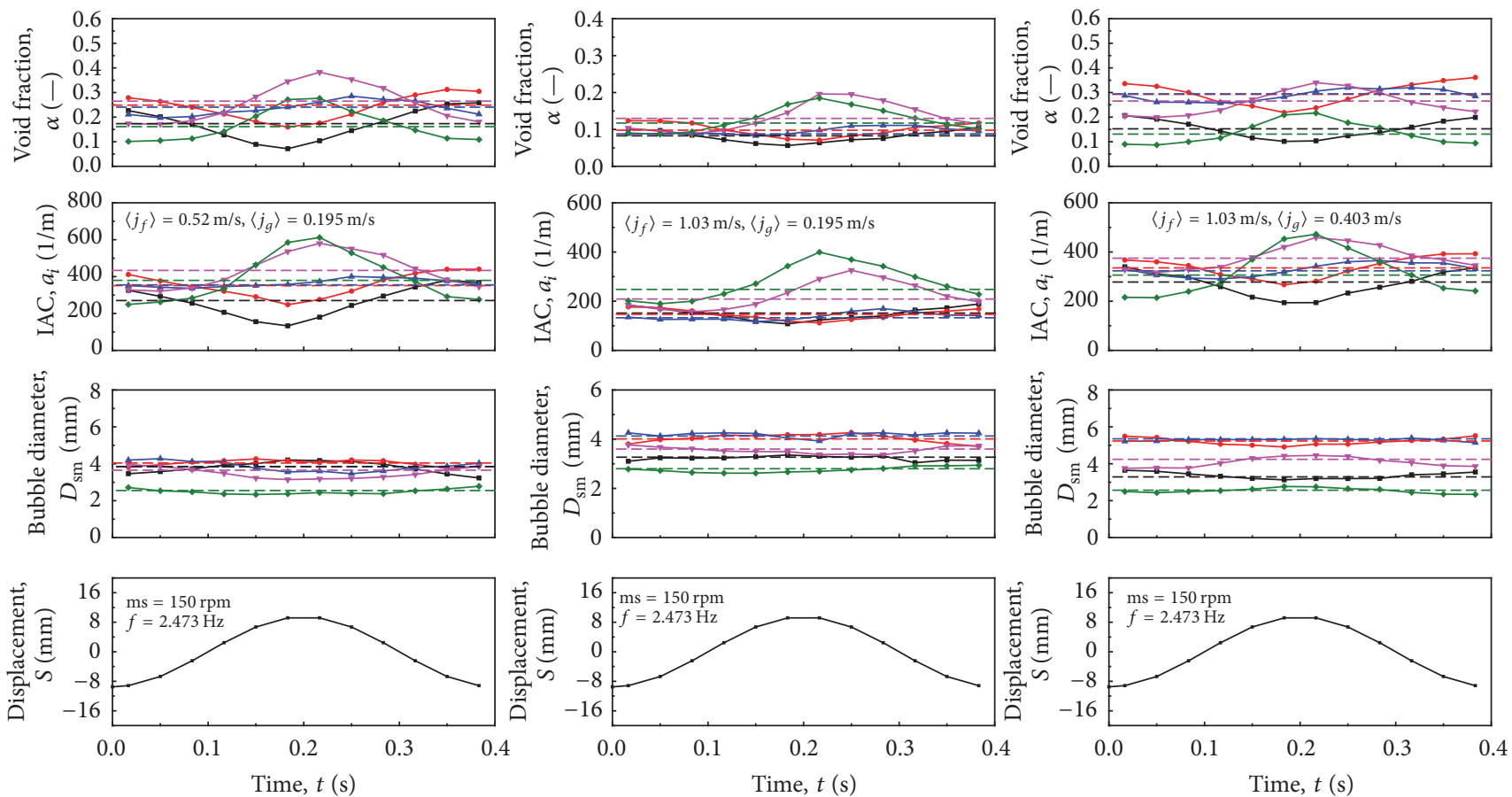

$$
\begin{aligned}
& \rightarrow r /\left(R_{o}-R_{i}\right)=0.13 \\
& \rightarrow r /\left(R_{o}-R_{i}\right)=0.52 \\
& \rightarrow r /\left(R_{o}-R_{i}\right)=0.91 \\
& \because r /\left(R_{o}-R_{i}\right)=0.33 \\
& \rightarrow r /\left(R_{o}-R_{i}\right)=0.72
\end{aligned}
$$

$$
\begin{aligned}
& \rightarrow r /\left(R_{o}-R_{i}\right)=0.13 \\
& \rightarrow r /\left(R_{o}-R_{i}\right)=0.52 \\
& \rightarrow r /\left(R_{o}-R_{i}\right)=0.91 \\
& \rightarrow r /\left(R_{o}-R_{i}\right)=0.33 \\
& \rightarrow r /\left(R_{o}-R_{i}\right)=0.72
\end{aligned}
$$$$
\begin{aligned}
& \rightarrow r /\left(R_{o}-R_{i}\right)=0.13 \\
& \rightarrow r /\left(R_{o}-R_{i}\right)=0.52 \\
& \rightarrow r /\left(R_{o}-R_{i}\right)=0.91 \\
& \rightarrow r /\left(R_{o}-R_{i}\right)=0.33 \\
& \rightarrow r /\left(R_{o}-R_{i}\right)=0.72
\end{aligned}
$$

Figure 6: Variation of local flow parameters in the vibration cycle. 

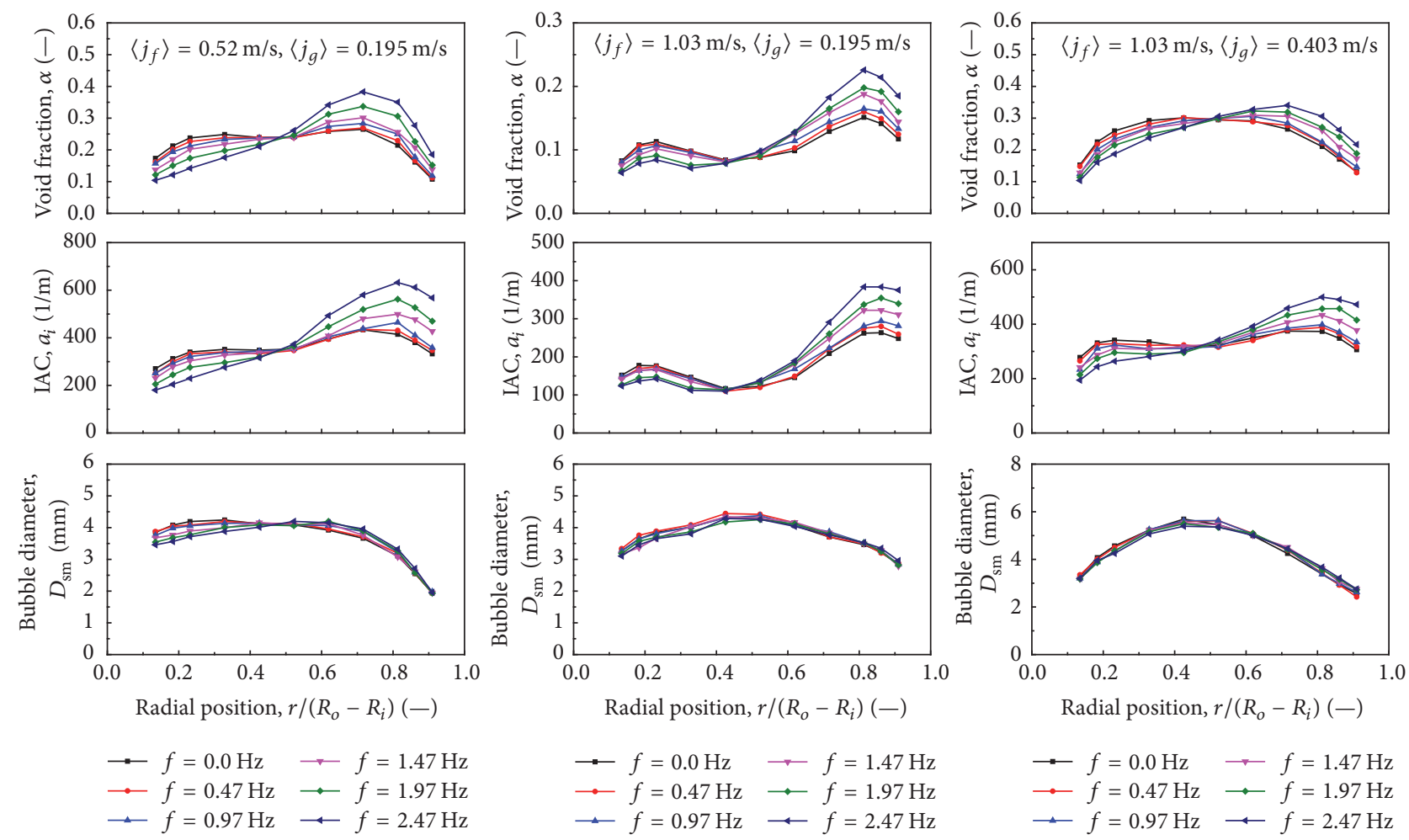

FIGURE 7: Vibration frequency effect on two-phase flow structure at vibration displacement of $S=S_{m 1}$.

The variation of bubble Sauter mean diameter in the vibration cycle is similar to that of the void fraction and interfacial area concentration, but the variation amplitude is much smaller. Thus, the vibration condition does not lead to much bubble coalescence or breakup in the present experiment. It can also be observed from Figure 7 that the fluctuation amplitude of the local flow parameters increases with vibration frequency. The absolute change of void fraction near the wall can reach more than $17 \%$ under vibration frequency of $f=2.473 \mathrm{~Hz}$. This indicates that the flow structure may change from finely dispersed bubbly flow to closely packed bubbly flow and the interfacial transport terms in the two-phase flow may be significantly changed.

It is important to note that, according to the design mechanism of the vibration module, the vibration of the test section is axisymmetric and the symmetry axis is defined as $z$-axis. The vibration acceleration of the test section is approximately symmetric in the positive and negative vibration directions, as shown in Figure 3. As a result, the lateral forces acting on bubbles including the additional force due to inertia and other interphase forces are almost symmetric with respect to $z$-axis. Therefore, the flows can be expected as axisymmetric under vibration condition and the measurement of two-phase flow along one radius is sufficient to reveal the two-phase flow behaviors in the vibration direction during structure vibration.

3.4. Vibration Frequency Effect on Variation of Local Flow Parameters. Two-phase flow structure at the vibration displacement of $S=S_{m 1}$ is used to investigate the vibration frequency effect on variation of local flow parameters. Vibration frequency $f$ ranges from $0.472 \mathrm{~Hz}$ to $2.473 \mathrm{~Hz}$. The radial distributions of local parameters under different vibration frequency are shown in Figure 7. The local time-averaged flow parameters measured under static condition are known as base values. As a comparison, these parameters are also shown in Figure 7 as the profiles indicted by $f=0.0 \mathrm{~Hz}$. As can be seen from the figure, the void fraction and interfacial area concentration are increased near the outer wall while decreased near the inner wall compared to the base values. This is consistent with the foregoing analysis and the phenomenon is enhanced with the increase of vibration frequency. When $f=0.5 \mathrm{~Hz}$, the vibration acceleration of the test section is within $0.014 \mathrm{~g}$ and the vibration velocity is less than $0.03 \mathrm{~m} / \mathrm{s}$. The additional bubble force due to inertia is rather small under this vibration condition. Therefore, the void fraction profile is almost the same as that in the stationary experiment. As the vibration frequency increases, the liquid inertia effect becomes significant and the additional bubble force increases greatly. As a result, radial bubble motions with bubbles moving toward outer wall become prominent as the test section moves from $S=0$ to $S=S_{m 1}$. When the vibration frequency increases to $2.473 \mathrm{~Hz}$, the peak near the inner wall is weakened $\left(\left\langle j_{f}\right\rangle=1.03 \mathrm{~m} / \mathrm{s}\right.$ and $\left.\left\langle j_{g}\right\rangle=0.195 \mathrm{~m} / \mathrm{s}\right)$ or even disappearing $\left(\left\langle j_{f}\right\rangle=0.52 \mathrm{~m} / \mathrm{s}\right.$ and $\left.\left\langle j_{g}\right\rangle=0.195 \mathrm{~m} / \mathrm{s}\right)$ and a strong peak skewed to outer wall is formed in the void fraction profile. From Figure 7 it can also be seen that the vibration effect on bubble Sauter mean diameter is not marked as compared with void fraction and interfacial area concentration. Therefore, bubble coalescence or breakup caused by structure vibration rarely occurs in bubbly two-phase flow. 

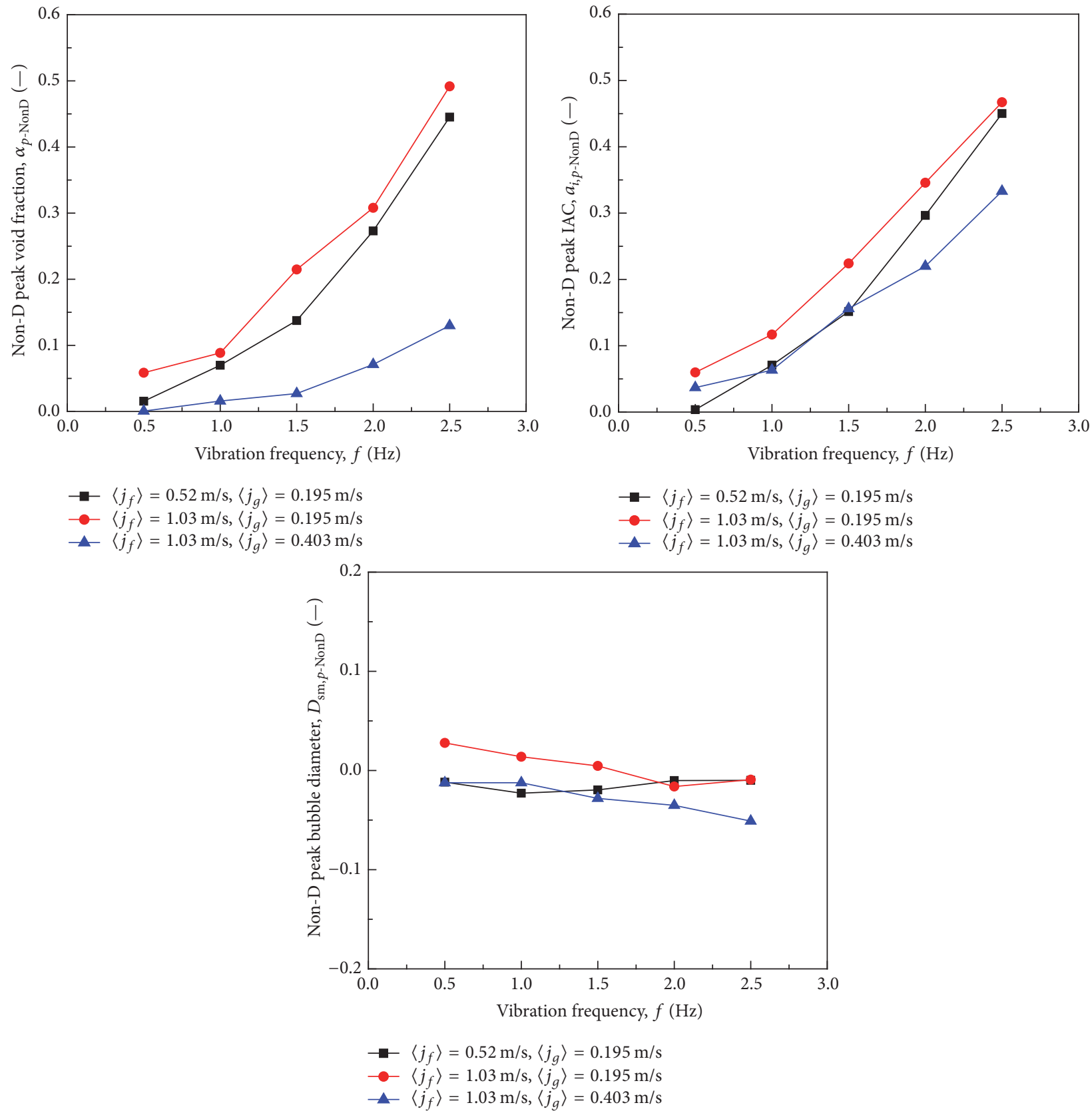

FIGURE 8: Vibration frequency effect on peak values of local flow parameters at $S=S_{m 1}$.

Figure 8 shows vibration frequency effect on the peak values of local flow parameters at vibration displacement of $S=S_{m 1}$. The nondimensional peak values have the following expressions:

$$
\begin{aligned}
\alpha_{p-\mathrm{NonD}} & =\frac{\left(\alpha_{p}-\alpha_{p 0}\right)}{\alpha_{p 0}}, \\
a_{i, p-\mathrm{NonD}} & =\frac{\left(a_{i, p}-a_{i, p 0}\right)}{a_{i, p 0}}, \\
D_{\mathrm{sm}, p-\mathrm{NonD}} & =\frac{\left(D_{\mathrm{sm}, p}-D_{\mathrm{sm}, p 0}\right)}{D_{\mathrm{sm}, p 0}},
\end{aligned}
$$

where $\alpha_{p \text {-NonD }}, a_{i, p \text {-NonD }}$, and $D_{\text {sm, } p \text {-NonD }}$ are the nondimensional peak values with respect to void fraction, interfacial area concentration, and Sauter mean diameter. The subscripts $p$ and $p 0$ denote the local peak values along the radius under vibration and static conditions, respectively. It can be seen from Figure 8 that the nondimensional peak void fraction and interfacial area concentration increase significantly with vibration frequency. Compared to the peak values measured in the stationary experiment, the peak void fraction can increase by $49 \%$ as the vibration frequency $f$ increases to $2.473 \mathrm{~Hz}$. But for the flow condition of $\left\langle j_{f}\right\rangle=1.03 \mathrm{~m} / \mathrm{s}$ and $\left\langle j_{g}\right\rangle=0.403 \mathrm{~m} / \mathrm{s}$, the nondimensional peak void fraction is much smaller. This may be attributed to strong mixing 

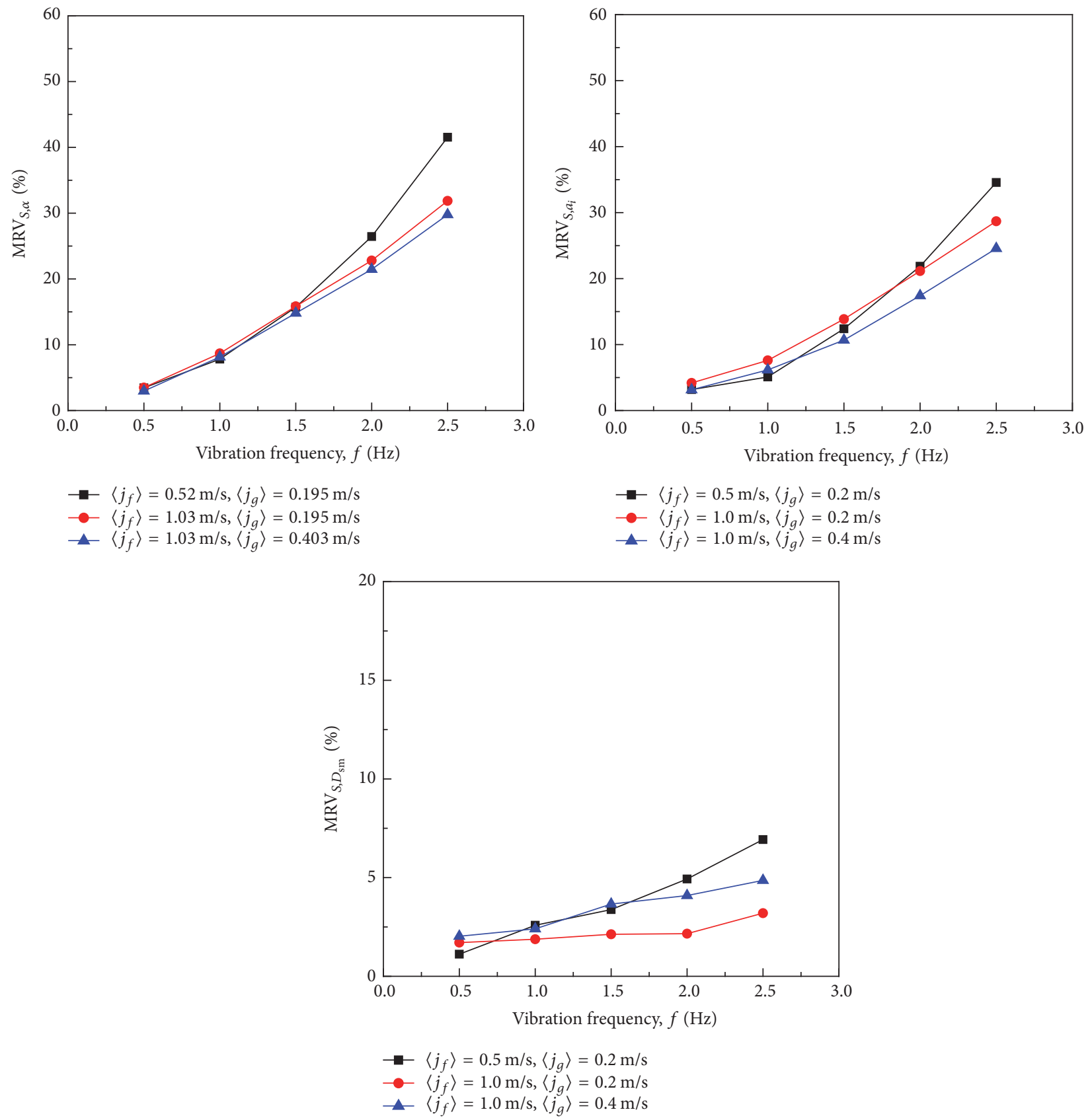

FIGURE 9: Vibration frequency effect on $\mathrm{MRV}_{S}$ of local flow parameters.

of two-phase flow due to bubble-induced turbulence. The nondimensional peak Sauter mean diameter is within $\pm 5 \%$, which means that structure vibration does not change bubble size greatly in the present experiment.

The average variation of local flow parameters throughout the 11 radial measurement locations is evaluated in this part through comparing the local parameters at vibration displacement of $S=S_{m 1}$ with base values in order to further reveal the vibration frequency effect. Similar to MRV, the mean relative variation at $S=S_{m 1}\left(\mathrm{MRV}_{S}\right)$ is defined for evaluation. The $\mathrm{MRV}_{S}$ has the same equations as MRV (i.e., (1)) except that the subscript $f$ is replaced by subscript $f$-S in the expressions of $\mathrm{MRV}_{S}$. Here, the subscript $f-S$ represents the local time-averaged values measured at the vibration displacement of $S=S_{m 1}$ with vibration frequency of $f$. The change of $\mathrm{MRV}_{S}$ with respect to vibration frequency is shown in Figure 9. As the vibration frequency $f$ increases from $0.472 \mathrm{~Hz}$ to $2.473 \mathrm{~Hz}$, the average change of local void fraction can reach more than $29 \%$ for all the flow conditions under consideration. The change in local void fraction is most obvious for low liquid velocity of $\left\langle j_{f}\right\rangle=0.52 \mathrm{~m} / \mathrm{s}$ with $\mathrm{MRV}_{S}$ of void fraction reaching up to $41 \%$ when $f=2.473 \mathrm{~Hz}$. The $\mathrm{MRV}_{S}$ of Sauter mean diameter also increases slightly with $f$, but the variation range is within $7 \%$. 


\section{Conclusions}

An experimental database has been collected in an annulus using double-sensor conductivity probe under vibration condition. The vibration amplitude of the test section is $9.5 \mathrm{~mm}$ and the vibration frequency ranges from $0.472 \mathrm{~Hz}$ to $2.473 \mathrm{~Hz}$. Local measurements have been performed along one radius in the vibration direction. The local time-averaged flow parameters including void fraction, interfacial area concentration, and Sauter mean diameter measured in the stationary experiment are used as base values in the analysis of vibration effect. Based on the experimental data, the vibration effect especially the vibration frequency effect on local parameters has been discussed and the following results have been obtained.

The vibration effect on local time-averaged flow parameters increases slightly with vibration frequency but the overall effect is very limited. Compared to the base values, the mean variation of local time-averaged flow parameters is within $8 \%$ and the vibration effect is further weakened as the void fraction increases. Local flow parameters fluctuate continuously around the respective base values in the vibration cycle and the fluctuation amplitude increases with vibration frequency. The absolute change of void fraction near the channel wall can reach $17 \%$ during the vibration cycle under vibration frequency of $f=2.473 \mathrm{~Hz}$. Additional bubble force due to inertia is found to play an important role in lateral bubble motions and the coaction of bubble forces determines the radial distribution of local parameters under vibration condition. With the increase of vibration frequency, the peak near the inner wall is weakened or even disappearing, and a strong peak skewed to outer wall is gradually observed in the void fraction and interfacial area concentration profiles at the vibration displacement of $S=S_{m 1}$. The nondimensional peak void fraction and interfacial area concentration increase significantly with vibration frequency and $\alpha_{p \text {-NonD }}$ can reach up to $49 \%$ at $f=2.473 \mathrm{~Hz}$. The average variations of local void fraction and interfacial area concentration along the radius also increase with vibration frequency. $\mathrm{MRV}_{S}$ of void fraction and interfacial area concentration can both increase to more than $25 \%$ for the flow conditions under consideration. But the increase of vibration frequency does not change bubble diameter significantly in the present work condition.

The current study shows that the vibration parameters have great influence on local parameters distribution under structure vibration and the vibration impact also varies with specific flow condition. Therefore, further study on vibration amplitude effect and the vibration effect on flow structure beyond bubbly flow is suggested.

\section{Nomenclature}

\section{General Symbols}

A: Vibration amplitude $(\mathrm{mm})$

a: Vibration acceleration $\left(\mathrm{m} / \mathrm{s}^{2}\right)$

$a_{i}$ : Interfacial area concentration $(1 / \mathrm{m})$

$D_{h}$ : Hydraulic diameter $(\mathrm{mm})$

$D_{\text {sm }}$ : Bubble Sauter mean diameter $(\mathrm{mm})$ $f:$ Vibration frequency $(\mathrm{Hz})$

g: Gravitational acceleration $\left(\mathrm{m} / \mathrm{s}^{2}\right)$

$j$ : Superficial velocity $(\mathrm{m} / \mathrm{s})$

L: Distance from the inlet port to the measurement port (mm)

ms: Motor speed (rpm)

$N$ : Total number of radial measurement locations

$r$ : Radial distance from inner rod wall $(\mathrm{mm})$

$R_{i}$ : Inner radius of annular channel ( $\left.\mathrm{mm}\right)$

$R_{o}$ : Outer radius of annular channel ( $\left.\mathrm{mm}\right)$

$S$ : Vibration displacement $(\mathrm{mm})$.

\section{Greek Letters}

$\alpha$ : Void fraction.

\section{Subscripts}

$a_{i}: \quad$ Interfacial area concentration term

$D_{\text {sm }}$ : Bubble Sauter mean diameter term

$f: \quad$ Liquid phase

$f=0$ : $\quad$ Local parameters measured under static condition

$f$-S: $\quad$ Local parameters measured at the maximum vibration displacement with vibration frequency of $f$

g: $\quad$ Gas phase

$m 1: \quad$ The maximum value in the positive vibration direction

$m 2: \quad$ The maximum value in the negative vibration direction

$p$ : $\quad$ Peak value in the local parameters profile under vibration condition

p0: $\quad$ Peak value in the local parameters profile under static condition

p-nonD: Nondimensional peak values

$\alpha: \quad$ Void fraction term.

Mathematical Symbols

\langle\rangle : Area-averaged value.

\section{Abbreviations}

IAC: Interfacial area concentration

IATE: Interfacial area transport equation

CFH: Critical heat flux

FFT: Fast Fourier transformation

MRV: Mean relative variations.

\section{Conflicts of Interest}

The authors declare that there are no conflicts of interest regarding the publication of this paper.

\section{Acknowledgments}

One of the authors Xiu Xiao would like to express her sincere appreciation for the financial support from China Scholarship Council (CSC). 


\section{References}

[1] G. Kocamustafaogullari and M. Ishii, "Foundation of the interfacial area transport equation and its closure relations," International Journal of Heat and Mass Transfer, vol. 38, no. 3, pp. 481-493, 1995.

[2] L. G. Neal and S. G. Bankoff, "A high resolution resistivity probe for determination of local void properties in gas-liquid flow," AIChE Journal, vol. 9, no. 4, pp. 490-494, 1963.

[3] I. Kataoka and A. Serizawa, "Interfacial area concentration in bubbly flow," Nuclear Engineering and Design, vol. 120, no. 2-3, pp. 163-180, 1990.

[4] S. T. Revankar and M. Ishii, "Theory and measurement of local interfacial area using a four sensor probe in two-phase flow," International Journal of Heat and Mass Transfer, vol. 36, no. 12, pp. 2997-3007, 1993.

[5] K. Yoneda, A. Yasuo, and T. Okawa, "Flow structure and bubble characteristics of steam-water two-phase flow in a largediameter pipe," Nuclear Engineering and Design, vol. 217, no. 3, pp. 267-281, 2002.

[6] X. Shen, K. Mishima, and H. Nakamura, "Two-phase phase distribution in a vertical large diameter pipe," International Journal of Heat and Mass Transfer, vol. 48, no. 1, pp. 211-225, 2005.

[7] G. Kocamustafaogullari and Z. Wang, "An experimental study on local interfacial parameters in a horizontal bubbly two-phase flow," International Journal of Multiphase Flow, vol. 17, no. 5, pp. 553-572, 1991.

[8] X. Yang, J. P. Schlegel, Y. Liu, S. Paranjape, T. Hibiki, and M. Ishii, "Experimental study of interfacial area transport in air-water two phase flow in a scaled $8 \times 8 \mathrm{BWR}$ rod bundle," International Journal of Multiphase Flow, vol. 50, pp. 16-32, 2013.

[9] D. Tian, C. Yan, L. Sun, P. Tong, and G. Liu, "Comparison of local interfacial characteristics between vertical upward and downward two-phase flows using a four-sensor optical probe," International Journal of Heat and Mass Transfer, vol. 77, pp. 11831196, 2014.

[10] X. Shen, H. Sun, B. Deng, T. Hibiki, and H. Nakamura, "Gasliquid bubbly flow structure in vertical large-diameter square duct," Progress in Nuclear Energy, vol. 89, pp. 140-158, 2016.

[11] S.-W. Chen, Experimental study of seismic vibration effect on two-phase flow [Ph.D. thesis], Purdue University, West Lafayette, Ind, USA, 2012.

[12] NRC, North Anna earthquake summary, 2011, https://www.nrc .gov/docs/ML1125/ML11259A220.pdf.

[13] H. Nariai and T. Tanaka, "Void fraction of subcooled flow boiling under oscillating heater rod," in Proceedings of the Annual Spring Meeting of Atomic Energy Society of Japan, no. J36, University of Tsukuba, Tsukuba, Japan, 1994.

[14] T. Hibiki and M. Ishii, "Effect of flow-induced vibration on local flow parameters of two-phase flow," Nuclear Engineering and Design, vol. 185, no. 2-3, pp. 113-125, 1998.

[15] Y. H. Lee, D. H. Kim, and S. H. Chang, "An experimental investigation on the critical heat flux enhancement by mechanical vibration in vertical round tube," Nuclear Engineering and Design, vol. 229, no. 1, pp. 47-58, 2004.

[16] S.-W. Chen, T. Hibiki, M. Ishii, M. Mori, and F. Watanabe, "Experimental study of adiabatic two-phase flow in an annular channel under low-frequency vibration," Journal of Engineering for Gas Turbines and Power, vol. 136, no. 3, Article ID 032501, 2014.
[17] R. Arai, K. Mizuno, A. Kaneko et al., "Development of prediction technology of two-phase flow dynamics under earthquake acceleration: 9-effect of structure vibration on rising bubble behavior," in Proceedings of the 21st International Conference on Nuclear Engineering (ICONE '13), Chengdu, China, August 2013.

[18] X. Xiao, Q. Zhu, G. Wang, S. W. Chen, M. Ishii, and Y. Zhang, "Vibration effects on bubbly flow structure in an annulus," in Proceedings of the 24th International Conference on Nuclear Engineering (ICONE '16), ICONE24-60735, Charlotte, NC, USA, June 2016.

[19] S. T. Revankar and M. Ishii, "Local interfacial area measurement in bubbly flow," International Journal of Heat and Mass Transfer, vol. 35, no. 4, pp. 913-925, 1992.

[20] T. Hibiki, S. Hogsett, and M. Ishii, "Local measurement of interfacial area, interfacial velocity and liquid turbulence in two-phase flow," Nuclear Engineering and Design, vol. 184, no. 2-3, pp. 287-304, 1998.

[21] T. Hibiki, R. Situ, Y. Mi, and M. Ishii, "Experimental study on interfacial area transport in vertical upward bubbly two-phase flow in an annulus," International Journal of Heat and Mass Transfer, vol. 46, no. 3, pp. 427-441, 2003.

[22] Q. Wu and M. Ishii, "Sensitivity study on double-sensor conductivity probe for the measurement of interfacial area concentration in bubbly flow," International Journal of Multiphase Flow, vol. 25, no. 1, pp. 155-173, 1999.

[23] D. Lucas, E. Krepper, and H.-M. Prasser, "Use of models for lift, wall and turbulent dispersion forces acting on bubbles for polydisperse flows," Chemical Engineering Science, vol. 62, no. 15, pp. 4146-4157, 2007.

[24] C. Morel, Mathematical Modeling of Dispersed Two-Phase Flows, Fluid Mechanics and Its Applications, Springer, 2015.

[25] Q. Wang and W. Yao, "Computation and validation of the interphase force models for bubbly flow," International Journal of Heat and Mass Transfer, vol. 98, pp. 799-813, 2016. 

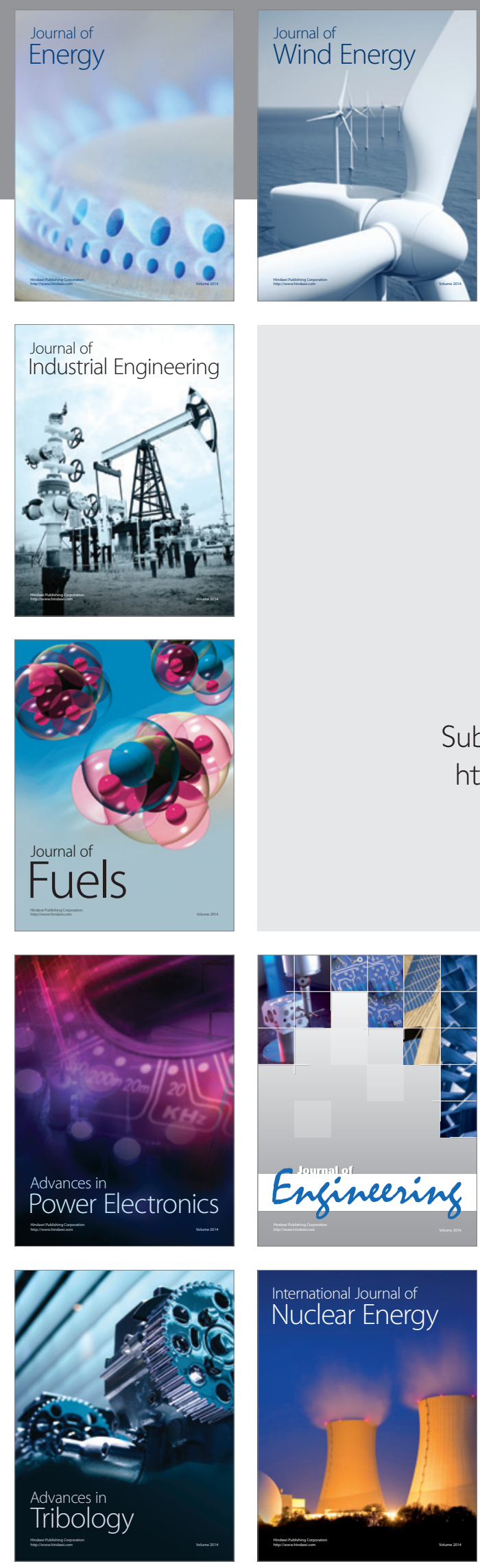

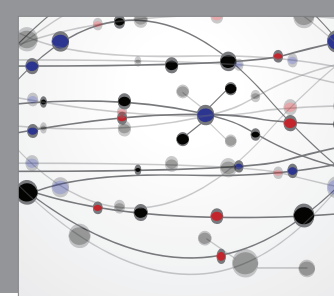

The Scientific World Journal
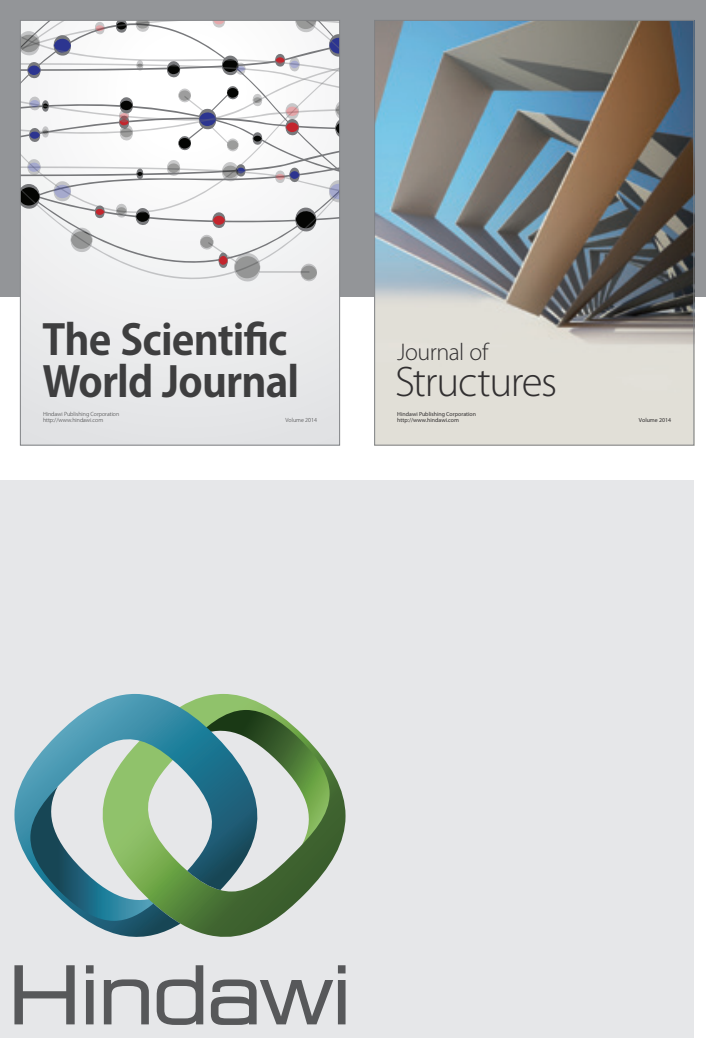

Submit your manuscripts at

https://www.hindawi.com
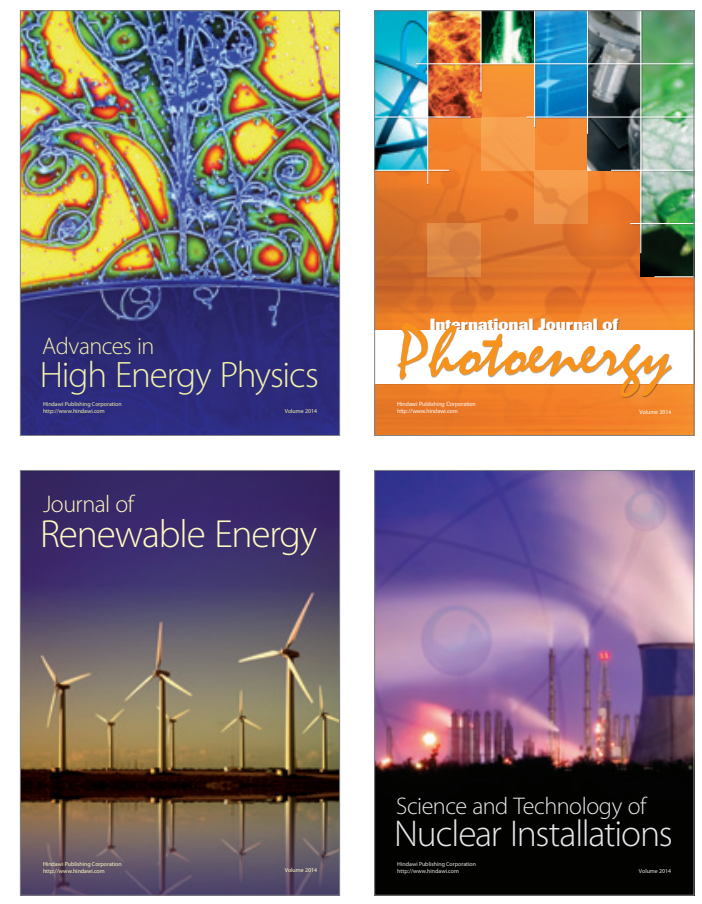
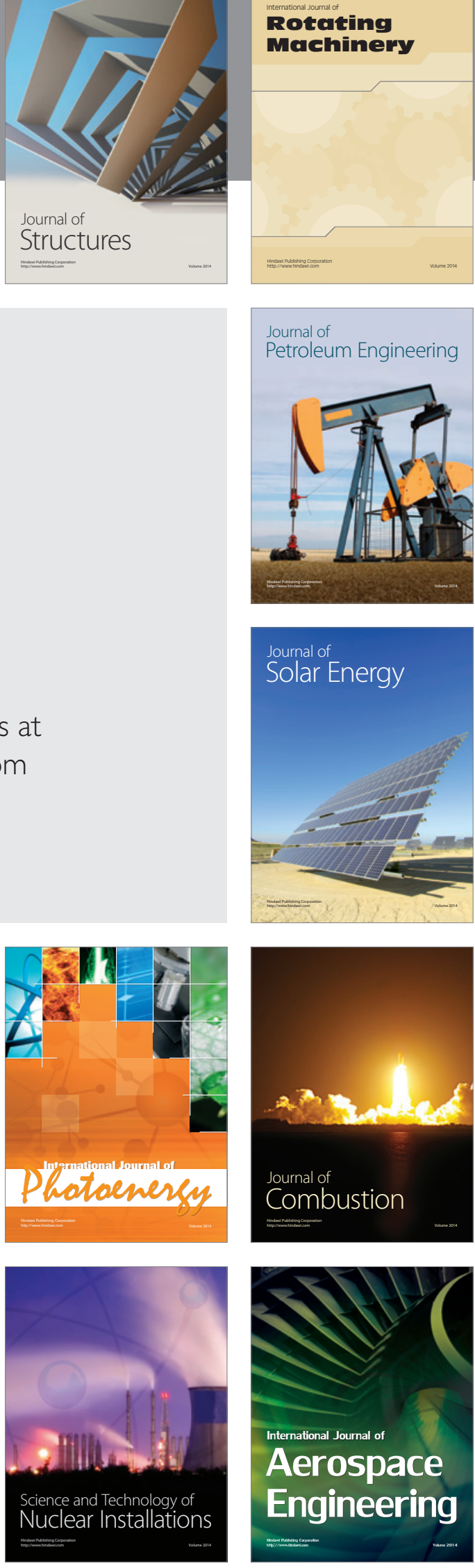